\title{
How Emergency Physicians' gender shaped by patients attending emergency departments in culturally conservative society?
}

\author{
Mohammed Alomar $^{1 *}$, Fatima Alkandari ${ }^{1}$, Muneera Al Asfoor ${ }^{1}$, Ali Almajed ${ }^{1}$, Sultan Alrobaian ${ }^{1}$, Ranya Abo Shanb ${ }^{1}$ and Abdelmoneim \\ Eldali $^{2}$ \\ ${ }^{1}$ Emergency Department, King Faisal Specialist Hospital and Research Centre, Saudi Arabia \\ ${ }^{2}$ Biostatistics Research unit, Research Centre, King Faisal Specialist Hospital and Research Centre, Saudi Arabia
}

\begin{abstract}
Background: Culturally conservative patients may feel uncomfortable when examined by opposite sex of EP (Emergency Physician).

Objective: To determines the preferred EP gender among ED (Emergency Department) patients and investigates which characteristics affect their choice

Design: Observational cross-sectional study.

Setting: Four major emergency departments.

Patients: Adults patients attending emergency departments.
\end{abstract}

Main outcome measures: Randomly selected patients answered a structured questionnaire detailing socio-demographic information and cultural status. Patients were asked about the preferred gender of EP in critical and non-critical presentation and the diverse characteristics of EP.

Categorical variables were summarized as frequencies, percentages and compared by Chi-square test. Univariate and multivariate logistic regression was used to assess the impact of important variables over gender preference. The level of statistical significance was set at $P<.05$.

Results: The interviewed 407 patients (56\% females) reflected a wide range of age, educational level, marital status, and occupation. In non-critical conditions, $41 \%$ of female patients preferred female EP which was statistically significant $(\mathrm{p}<0.004)$. In critical conditions, $27 \%$ of female patients preferred female EP. Experience, concerning, trustfulness and making the patient comfortable were the major characteristic features among EP.

Using univariate logistic regression in non-critical conditions for female EP preference; the significant factors are: origin $(P=.02)$, gender $(P<.0001)$, age $(\mathrm{p}=0.006)$, and occupation $(P=.01)$. While in multivariate logistic regression only gender and age was found to be significant $(\mathrm{p}<.0001),(P=.01)$ respectively. Univariate logistic regression in critical conditions for female EP preference found the significant factors are: gender $(P<.0001)$, occupation $(P<.0001)$, and religion commitment $(P=.03)$. While in multivariate logistic regression only gender and occupation were found to be significant $(P<.0001),(P=.004)$ respectively.

Conclusions: Both genders of EP are needed in emergency departments, however, more female EPs are needed for the delivery of high-quality gender-sensitive healthcare in ED.

\section{Background}

Emergency Department (ED) is a highly specialized critical care center and admits, discharge, or refer patients. In critical and highly emergent care situations, rapid communication is key to providing optimum care. Patient reassurance and trust is an important aspect of cultural communication in Emergency situations, especially for culturally conservative patients who may feel uncomfortable when examined by opposite sex [1,2].

Research indicates that physician-patient communication has a significant influence on the outcome of patient care, including patient satisfaction, compliance to treatment, recall and understanding of medical information, coping with the disease and even actual state of health [3-8].

Gender relations in the medical context given cultural ethics concerning cross-gender interaction one can understand how the medical arena may be uncomfortable for some culturally conservative people. The challenge for providers is to understand and recognize when, cultural conceptions of modesty might make patients reticent to change their dress, to expose parts of their body for examination by a member of the opposite sex even in the presence of a chaperone.

Cultural needs in Emergency Medicine is an important concern raised and discussed in the literature [9]. Which in turn might affect diagnosis and treatment and, therefore, awareness and fulfilment of

Correspondence to: Mohammed Alomar, MBC 84, Emergency Department, King Faisal Specialist Hospital and Research Centre, PO Box 3354, Riyadh 11211, Saudi Arabia, Tel: 966114424425; E-mail: momar@kfshrc.edu.sa

Key words: Emergency, Department, Physician, Patient, Gender, Culture

Received: January 07, 2018; Accepted: January 26, 2018; Published: January 30, 2018 
the needs might reduce health disparities [10]. Culture includes values, beliefs, customs, and ways of thinking, the explanation of disease and its progression, and patient compliance. These beliefs range broadly from disease causation, interpretation of symptoms, and appropriate treatment and prevention, to values attached to medical interventions and physical examination [11-15].

Women in some culture advised covering their hair, body, arms, and legs at any time she meets stranger men. That is including physical contact with opposite gender medical care providers, except in cases of medical emergencies [16]. This framework explains why many prefer to see a same-sex physician, particularly in consultations necessitating examination of the genitalia despite the standard practice calls for chaperones when conducting opposite sex examinations [17].

Emergency medicine specialty has traditionally been a male specialty and remains so in spite of increasing female representation [18]. Internationally, Female medical school graduates have been increasing, as has the number of females entering emergency medicine [19].

Licensed emergency medicine consultants in Saudi Arabia is less than $1 \%$ of all other specialties and the number of female emergency medicine residents, as well as female consultants, licensed to practice emergency medicine in Saudi Arabia is still low $<1 \%$ [20,21].

This descriptive study determines the preferred EP gender among ED (Emergency Department) patients and investigates which characteristics affect their choice.

\section{Methods}

\section{Aim and hypothesis}

We hypothesized that ED patients chose the same of their gender, hence the aim of this study was to examine their gender preference. A structured survey was distributed to patients attending four major tertiaries and teaching emergency departments (EDs) in an urban big city. These emergency departments are representing a range of socioeconomic strata. Participants were randomly selected to match the investigators' schedule, which was randomly distributed, including morning, evening, and night shifts. The permission of the ED director and consent of the participant were obtained verbally, emergency medicine residents and pediatric emergency fellows administered the surveys.

\section{Development of questions}

A suitable survey was constructed and the questions were developed on the following steps.

1. Literature had been searched for existing surveys on EP gender preference.

2. A survey of a culture similar to the study population has not been found.

\section{A self-reported 14-item questionnaire was developed.}

4. The first part of the questionnaire gathered basic sociodemographic data (age, country of origin, family status, cultural status, education, and employment).

5. The culture conservative status of the respondents was classified into one of three subgroups; secular, conservative and extremely conservative. The classification was measured according to their self-definition and estimation (the self-estimation has evaluated their intensity of belief and accordingly life habits).
6. The second part, the patients were asked about their gender preferences for EP, and in the last part, they were asked about diverse characteristics they sought in their preferred EP.

7. The survey was written in two versions Arabic and English.

8. The survey was pre-tested on trial at one of the hospitals included on the study for accuracy and ease of administration, and to identify problematic questions and edit them appropriately.

9. No ambiguous questions had been found after a trial of pre-testing for validity and feasibility.

\section{Timeline and sample size}

The study was conducted over 6 months. The calculated sample size needed to be 367 subjects based on $95 \%$ confidence level and probable error of $5 \%$. Given that some participants may have withdrawn; the sample size was increased to 400 participants.

\section{Inclusion and exclusion}

Adults' patients attending EDs with Canadian Acuity Triage Acuity Scale (CTAS) level II were included. A participant with Canadian Acuity Triage Acuity Scale (CTAS) level I, Intoxicated, Geriatric, Demented, Major psychiatric disorders and participants not providing informed consent were excluded.

Non-Arabic-speaking respondents were aided by translators.

\section{Statistical analysis}

Data were analyzed using SAS, version 9.3 (SAS Institute Inc., Cary, NC, USA). Descriptive statistics for the categorical variables were summarized as frequencies, percentages and compared by Chi-square test. Univariate and multivariate logistic regression was used to assess the impact of important variables over gender preference. The level of statistical significance was set at $P<.05$.

\section{Participants Information and Consent}

Participants were informed that this study aimed to assess patients' preference of EP gender in Saudi Arabia. Participants were asked about their burn experience, use of first aid, and the best means of conveying the initial management and prevention program. At the beginning of the interview, one of the investigators obtained verbal informed consent from the participants. The Office of Research Affairs approved the study, and confidentiality of data collection was protected.

\section{Work plan}

The participants were interviewed over 4 months by the coinvestigator. The collected data were managed in the fifth month by the principal investigator. Then, the data were statistically managed by the statistician and the principal investigator.

\section{Results}

Four major tertiary care and teaching hospitals were sites of recruitment with a total of 407 participants being interviewed (hospital A 101, hospital B 101, hospital C 101, and hospital D 104). (Figure 1). The participating hospitals were the base training centers for the emergency medicine residency training program, with no major socioeconomic variation found among them.

The participant $(56 \%$ females) reflected a wide range of age, educational level, marital status and occupation (Table 1). Using Chisquare test the data showed a significant association between the four 


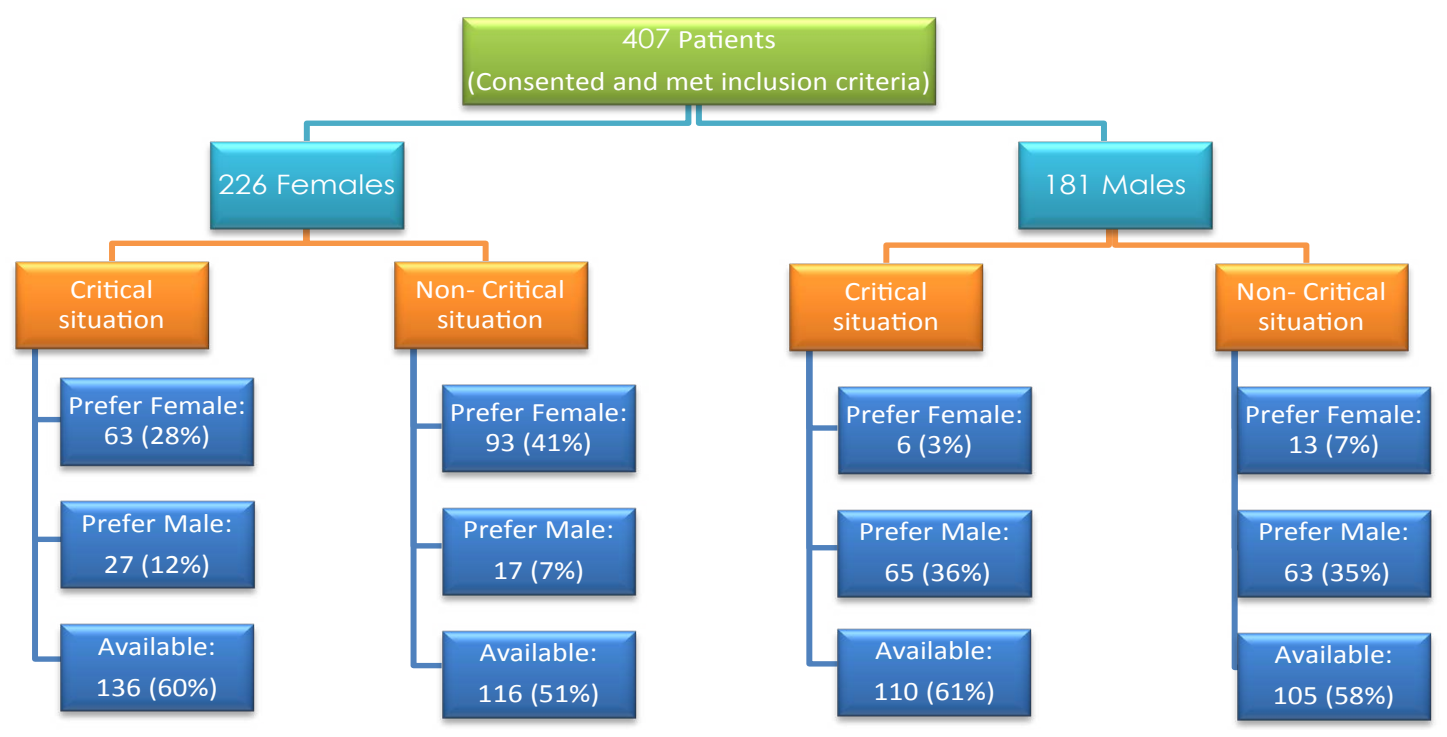

Figure 1. The population of participants recruited for the gender study.

Table 1. Patients characteristics.

\begin{tabular}{|c|c|}
\hline Characteristic & $\begin{array}{l}\text { Number (\%) } \\
\text { Total }=\mathbf{4 0 7}\end{array}$ \\
\hline \multicolumn{2}{|l|}{ Origin } \\
\hline Middle East & $315(77)$ \\
\hline Asia & $65(16)$ \\
\hline Africa & $14(3)$ \\
\hline Europe & $8(2)$ \\
\hline South, North America, and others & $5(2)$ \\
\hline \multicolumn{2}{|l|}{ Sex } \\
\hline female & $226(56)$ \\
\hline Male & 181(44) \\
\hline \multicolumn{2}{|l|}{ Age } \\
\hline$<30$ & $174(42)$ \\
\hline $31-40$ & $122(30)$ \\
\hline $41-50$ & $49(12)$ \\
\hline $51-60$ & $39(10)$ \\
\hline$>60$ & $23(6)$ \\
\hline \multicolumn{2}{|l|}{ Marital status } \\
\hline Married & 213(52) \\
\hline single & $140(34)$ \\
\hline Separated & $37(9)$ \\
\hline divorced & 11(3) \\
\hline Widowed & $6(2)$ \\
\hline \multicolumn{2}{|l|}{ Occupation } \\
\hline Government employee & $157(59)$ \\
\hline Housewife & $74(18)$ \\
\hline Private sector employee & $66(16)$ \\
\hline Student & $59(14)$ \\
\hline Unemployed & $29(7)$ \\
\hline Retired & $24(6)$ \\
\hline \multicolumn{2}{|l|}{ Education level } \\
\hline Primary & $62(15)$ \\
\hline Intermediate & $56(14)$ \\
\hline Secondary & $95(23)$ \\
\hline University & 179(44) \\
\hline Higher education & $15(4)$ \\
\hline \multicolumn{2}{|l|}{ Cultural Commitment } \\
\hline Committed & $322(79)$ \\
\hline Extremely committed & $43(11)$ \\
\hline Secular & $42(10)$ \\
\hline
\end{tabular}

centers and religious commitment of the patients $(P=.02)$

After patients who chose the available option excluded, forty-six percent of the patients (20\% prefer males and $26 \%$ prefer females) have physician gender preference in non-critical conditions. In the critical presentation, $40 \%$ have the preference (22\% prefer male physician and $17 \%$ prefer female physician).

In non-critical condition; $41 \%$ of female patients preferred female EP which was statistically significant $(P<.004) .8 \%(17)$ of females prefer male physician. Three percent (6) of males prefer female physician (Figure 2).

In critical condition; $12 \%(27)$ of female chose a male physician. $27 \%$ of female patients preferred female EP. 3\% (6) of males prefer female physician. $36 \%$ ( 65) of males prefer male physician.

Experience, concerning, trustfulness and making the patient comfortable were the major characteristic features among EP (Tables 2 and 3 ).

With using univariate logistic regression in non-critical conditions for female EP preference; the significant factors are: origin $(P=.02)$, gender $(P<.0001)$, age $(P=.006)$, and occupation $(P=.01)$. Using multivariate logistic regression only gender and age was found to be significant $(P<.0001),(P=.01)$ respectively. With using univariate logistic regression in critical conditions for female EP preference; the significant factors are: gender $(P<.0001)$, occupation $(P<.0001)$, and religion commitment $(P=.03)$. Using multivariate logistic regression only gender and occupation were found to be significant $(P<.0001),(P$ $=.004$ ) respectively.

\section{Discussion}

This unique study in ED setting showed half of the patients have a gender preference. Female patients preferred female ED physician especially during internal examinations in non-critical situations. However, this preference might be ignored in case of critical situations (Figure 2). Though no similar ED studies, however, this attitude has not really changed half a century ago, neither where women preferred female gynecologists nor recently as demonstrated by Bashour et al. when reported that more than $85 \%$ of Syrian preferred their obstetrician to be a female [22-36]. Similar results found by Lafta et al. where $74 \%$ 


\section{The Preferred Physician Gender}

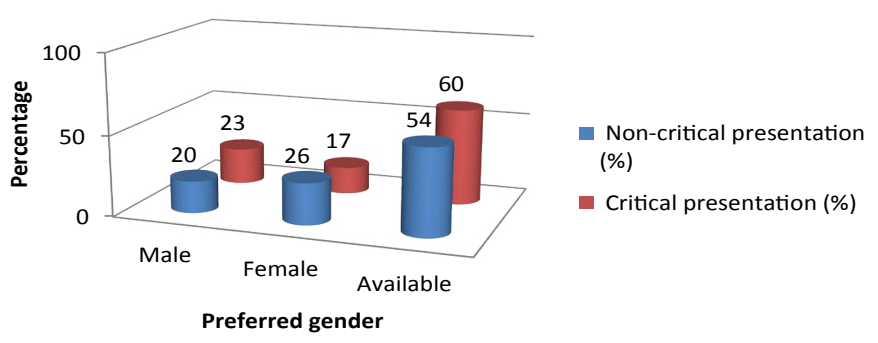

Figure 2. The preferred physician gender in critical and non-critical presentation.

Table 2. Factors related to the patients.

\begin{tabular}{|c|c|}
\hline Factors related to the patients & $\begin{array}{c}\text { Number (\%) } \\
\text { Total } \mathbf{4 0 7}\end{array}$ \\
\hline Makes me comfortable & $112(28)$ \\
\hline I Trust & $93(23)$ \\
\hline Show concern to me & $78(19)$ \\
\hline My Religion commitment & $40(10)$ \\
\hline More Friendly to me & $20(5)$ \\
\hline Respect me & $16(4)$ \\
\hline Spend enough time with me & $5(1)$ \\
\hline Don't know & $43(11)$ \\
\hline
\end{tabular}

Table 3. Factors related to the chosen physician gender.

\begin{tabular}{|c|c|}
\hline Characteristics features of the physician & $\begin{array}{c}\text { Number (\%) } \\
\text { Total }=\mathbf{4 0 7}\end{array}$ \\
\hline Experience & $188(46)$ \\
\hline Skill & $49(12)$ \\
\hline Moral & $47(11)$ \\
\hline International Certification & $19(5)$ \\
\hline Religion commitment & $13(3)$ \\
\hline Knowledge & $13(3)$ \\
\hline Country of origin & $7(2)$ \\
\hline National Certification & $4(1)$ \\
\hline Age & $4(1)$ \\
\hline Don't know & $66(16)$ \\
\hline
\end{tabular}

of Iraqi female patients preferred female gynecologists, $8 \%$ preferred male gynecologists and $18 \%$ had no gender preference [37]. In 2005, Rizk et al. carried out a survey on gender preference and other factors in gynecologist/ obstetrician preference in the United Arab Emirates (UAE) in which the majority of participants (95\%) were culturally conservative (Muslims). They found that gender ranked as one of the important factors for selection, regardless of other relevant factors [38].

The current study found trust, showing concerns and making the patient comfortable determines physician gender selection, which was consistent with what Deorase et al found [39]. However, the culture commitment was a major factor related to patient decision toward their physician gender selection, which is matching with some other studies [33,36,37]. Several studies have demonstrated variation in communication patterns between physician and patient's gender, which influence healthcare outcomes and cost savings [40-43]. Some studies showed female physicians to be more empathetic in communication style and spend longer time with patients, gather information about psychosocial issues and involve patients in decision making than their male colleagues $[44,45]$.

Other studies have shown that female physicians adhere to clinical guidelines as our finding showing that women trusted female physicians more than they trusted male physicians is important, since recent research found that patients' trust in their physicians was a major correlate of patient adherence, satisfaction, provide preventive care more often and improved health status [46-49].

Though few of our male patients preferred female physicians, studies showed either they rated them equally or they were more satisfied $[26,34,39]$.

As more ED physicians are needed, teams should include women physicians not only because more emergency physicians are needed within the medical community but because the ideas, skills, interests, and creativity women bring are essential to the ongoing success of the EM specialty [50].

Given the tendency towards women's greater satisfaction with female physicians, male clinicians should be sensitized to the possibility that female patients may have different preferences in their interactions with physicians. It is possible that with attention to the communication skills during training, male physicians may be able to learn how to better communicate with their female patients. There also may be a component of the female-female dyad that is not transferable, meaning that no matter how hard male physicians try, female patients will still prefer female physicians. The study will help in the development of appropriate strategies for the implementation of knowledge about physician and patient gender differences, which will be crucial for the delivery of high-quality gender-sensitive healthcare [51,52].

\section{Conclusions}

Both genders of EP are needed in emergency departments, however, more female EPs are needed for the delivery of high-quality gendersensitive healthcare in ED.

\section{Limitations}

This study is limited by lack of objective measures of patientphysician interaction in order to calibrate patient perspectives like time spent with the patient. Though the spent time by physicians was not a major determinant factor for choosing physician gender as would expect that all ED physicians, regardless of their gender, would be under similar time constraints. This is inconsistent with previous studies that showed same gender dyads tend to have longer visits than opposite gender dyads (longest between female physicians and female patients and shortest between male physicians and female patients [50].

Second, we didn't control for several other potential cofounders: triage, waiting time before seen by a physician, laboratory and radiological turnaround times. We don't expect a lack of these data may affect the patient selection of the gender type.

\section{References}

1. Richardson LD, Babcock Irvin C, Tamayo-Sarver JH (2003) Racial and ethnic disparities in the clinical practice of emergency medicine. Acad Emerg Med 10: 11841188. [Crossref]

2. Weaver C, Sklar D (1980) Diagnostic dilemmas and cultural diversity in emergency rooms. West J Med 133: 356-366. [Crossref]

3. Street RL Jr, Krupat E, Bell RA, Kravitz RL, Haidet P (2003) Beliefs about control in the physician patient relationship: effect on communication in medical encounters. $J$ Gen Intern Med. 18(8): 609-616.

4. Hagihara A, Tarumi K (2006) Doctor and patient perceptions of the level of doctor explanation and quality of patient-doctor communication. Scand J Caring Sci. 20(2): $143-150$

5. Brédart A, Bouleuc C, Dolbeault S (2005) Doctor-patient communication and satisfaction with care in oncology. Curr Opin Oncol 17: 351-354. [Crossref] 
6. Ishikawa H, Takayama T, Yamazaki Y, Seki Y, Katsumata N (2002) Physician-patient communication and patient satisfaction in Japanese cancer consultations. Soc Sci Med. 55(2): 301- 311

7. Eide H, Graugaard P, Holgersen K, Finset A (2003) Physician communication in different phases of a consultation at an oncology outpatient clinic related to patient satisfaction. Patient Educ Couns. 51(3): 259-266.

8. Main CJ, Buchbinder R, Porcheret M, Foster N (2010) Addressing patient beliefs and expectations in the consultation. Best Pract Res Clin Rheumatol. 24(2): 219-225.

9. American College of Emergency Physicians (2008) Cultural awareness and emergency care. Ann Emerg Med 52: 189. [Crossref]

10. Padela A, Gunter K, Killawi A, Heisler M (2012) Religious values and healthcare accommodations: voices from the American Muslim community. J Gen Inter Med. 27:708-15.

11. Padela AI, Del Pozo PR (2011) Muslim patients and cross-gender interactions in medicine: An Islamic bioethical perspective. Journal of medical ethics. 37(1):40.

12. Padela AI (2007) Can you take care of my mother? Reflections on cultural competency and clinical accommodation. Acad Emerg Med 14: 275-277. [Crossref]

13. Hamilton G, Marco CA (2003) Emergency medicine education and health care disparities. Acad Emerg Med 10: 1189-1192. [Crossref]

14. Brach C, Fraserirector I (2000) Can cultural competency reduce racial and ethnic health disparities? A review and conceptual model. Med Care Res Rev. 57(Suppl 1):181-217.

15. Reitmanova S (2008) "they can’t understand it": Maternity health and care needs of immigrant Muslim women in St. John's, Newfoundland. Mater Child Health J. 12:10111

16. Scheinberg AC (2006) Modesty and healthcare for women: understanding cultura sensitivities. Commun Oncol. 3:443-6.

17. Dhami S, Sheikh A (2000) The Muslim family: predicament and promise. West J Med 173: 352-356. [Crossref]

18. Bowman M, Gross ML (1986) Overview of research on women in medicine--issues for public policy makers. Public Health Rep. 101(5):513-521.

19. Association of American Medical Colleges (1982) US Medical School Applicants and Students 1982-1983 to 2011-2012. https://www.aamc.org/download/153708/data/ charts1982to2012.pdf. Accessed November 10, 2016.

20. Saudi Specialty Certificate of Pediatrics, and Emergency Medicine Training Programs (2016) Available at: http://english.scfhs.org.sa/index. Accessed April 10.

21. Saudi Arabian Ministry of health statistics book (2015) Available at: http://www.moh gov.sa/en/Ministry/Statistics/book. Accessed May 20, 2016.

22. Neubardt SB (1974) moderator. Women's liberation and the male gynecologist [Roundtable]. Med Aspect Hum Sex. 8:158-99.

23. Engstrom S, Madlon-Kay DJ (1998) Choosing a family physician. What do patients want to know? Minn Med 81: 22-26. [Crossref]

24. Hill CJ, Garner SJ (1991) Factors influencing physician choice. Hosp Health Serv Adm 36: 491-503. [Crossref]

25. Elstad JI (1994) Women's priorities regarding physician behavior and their preference for a female physician. Women Health. 21:1-19.

26. Schmittdiel J, Selby JV, Grumbach K, Quesenberry Jr CP (1999) Women's provider preferences for basic gynecology care in a large health maintenance organization. $J$ Womens Health Gend Based Med. 8:825-33.

27. Chandler PJ, Chandler C, Dabbs ML (2000) Provider gender preference in obstetrics and gynecology: a military population. Mil Med 165: 938-940. [Crossref]

28. Plunkett BA, Milad MP (2000) How a woman selects her gynecologic surgeon and obstetrician and which factors are important to her. J Gynecol Surg. 16: 107-11.

29. Baskett TF (2002) What women want: don't call us clients, and we prefer female doctors. J Obstet Gynaecol Can. 24:572-4.

30. Roter DL, Geller G, Bernhardt BA, Larson SM, Doksum T (1999) Effects of obstetrician gender on communication and patient satisfaction. Obstet Gynecol. 93: 635-41.

31. Fisher WA, Bryan A, Dervaitis KL, Silcox J, Kohn H (2002) It ain't necessarily so: most women do not strongly prefer female obstetrician-gynaecologists. $J$ Obstet Gynaecol Can. 24:885-8.

32. Zuckerman M1, Navizedeh N, Feldman J, McCalla S, Minkoff H (2002) Determinants of women's choice of obstetrician/gynecologist. J Womens Health Gend Based Med 11: $175-180$. [Crossref]
33. Haar E, Halitsky V, Stricker G (1975) Factors related to the preference for a female gynecologist. Med Care 13: 782-790. [Crossref]

34. Howell EA, Gardiner B, Concato J (2002) Do women prefer female obstetricians? Obstet Gynecol 99: 1031-1035. [Crossref]

35. Amir H, Hazan M, Amit A, Azem F (2010) Unexpected preference of obstetrician and gynecologists by ultra-orthodox Jewish women. In: Abstract book of the 16th International Congress of the International Society of Psychosomatic Obstetrics and Gynecology.

36. Bashour H, Abdulsalam A (2005) Syrian women's preferences for birth attendant and birth place. Birth 32: 20-26. [Crossref]

37. Lafta RK (2006) Practitioner gender preference among gynecologic patients in Iraq Health Care Women Int. 27:125-30.

38. Rizk DE, El-Zubeir MA, Al-Dhaheri AM, Al-Mansouri FR, Al-Jenaibi HS (2005) Determinants of women's choice of their obstetrician and gynecologist provider in the UAE. Acta Obstet Gynecol Scand. 84:48-53.

39. Derose KP, Hays RD, McCaffrey DF, Baker DW (2001) Does physician gender affect satisfaction of men and women visiting the emergency department? J Gen Intern Med. 16:218-26.

40. Dale J, Sandhu H, Lall R, Glucksman E (2008) The patient, the doctor and the emergency department: a cross-sectional study of patient-centredness in 1990 and 2005. Patient Educ Couns. 72:320-9.

41. Kaplan SH, Greenfield S, Gandek B, Rogers WH, Ware JE Jr (1996) Characteristics of physicians with participatory decision-making styles. Ann Intern Med 124: 497-504. [Crossref]

42. Bertakis K, Callahan E, Helms LJ, Azari R, Robbins J, Miller J (1998) Physician practice styles and patient outcomes: differences between family practice and general internal medicine. Med Care. 36:879-91.

43. Ross S (2003) The feminization of medicine. Am Med Assoc J Ethics. 5 (available from URL: http://virtualmentor.ama-assn.org/2003/09/msoc1-0309.html).

44. Roter DL, Hall JA, Aoki Y (2002) Physician gender effects in medical communication: a meta-analytic review. J Am Assoc. 288:756-64.

45. Elstad JI (1994) Women's priorities regarding physician behaviour and their preference for a female physician. Women Health. 21:1-19.

46. Roter DL, Hall JA (2006) Doctors talking with patients/patients talking with doctors Improving communication in medical visits, 2 nd ed., London: Praeger.

47. Berthold HK, Gouni-Berthold I, Bestehorn KP, Böhm M, Krone W (2008) Physician gender is associated with the quality of type 2 diabetes care. J Intern Med 264: 340 350. [Crossref]

48. Baumhäkel M, Müller U, Böhm M (2009) Influence of gender of physicians and patient on guideline-recommended treatment of chronic heart failure in a cross-sectional study. Eur J Heart Fail 11: 299-303. [Crossref]

49. Frank E, Dresner Y, Shani M, Vinker S (2013) The association between physicians' and patients' preventive health practices. CMAJ. 185(8): 649-653.

50. Gross DA, Zyzanski SJ, Borawski EA, Cebul RD, Stange KC (1998) Patient satisfaction with time spent with their physician. J Fam Pract 47: 133-137. [Crossref]

51. Maximizing the potential for women in emergency medicine. (2017) ACEP website Available at: http://www.acep.org/Physician-Resources/Policies/Policy- Statements Maximizing-the-Potential-of-Women-in-Emergency-Medicine. Accessed April.

52. Choo EK, Kass D, Westergaard M, et al. (2016) The development of best practice recommendations to support the hiring, recruitment and advancement of women physicians in emergency medicine. Acad Emerg Med. 23(11):1203-1209.

Copyright: (C)2018 Alomar M. This is an open-access article distributed under the terms of the Creative Commons Attribution License, which permits unrestricted use, distribution, and reproduction in any medium, provided the original author and source are credited. 